http://doi.org/10.18619/2072-9146-2019-4-80-84 УДК 635.342:631.563.6

Посокина Н.Е.,

Захарова А.И.

Всероссийский научно-исследовательский институт технологии консервирования - филиал Федерального государственного бюджетного научного учреждения «Федеральный научный центр пищевых систем им. В.М. Горбатова» РАН (ВНИИТеК - филиал ФГБНУ «ФНЦ пищевыХ систем им. В.М. Горбатова» РАН) www.vniitek.ru

E-mail: labtech45@yandex.ru

Ключевые слова: обзор, процесс ферментации овощей, молочнокислые микроорганизмы, безопасность и качество готовой продукции.

Конфликт интересов: Авторы заявляют об отсутствии конфликта интересов.

Для цитирования: Посокина Н.Е., Захарова А.И Молочнокислые микроорганизмы, создающие оптимальные стартовые условия для процесса ферментации капусты белокочанной. Овощи России. 2019;(4):80-84.

https://doi.org/10.18619/2072-9146-2019-4-80-84

Поступила в редакцию: 23.04.2019

Опубликована: 25.08.2019

Nataliya E. Posokina,

Anna I. Zakharova

Russian Research Institute

of Canning Technology -

Branch of V.M. Gorbatov Federal Research Center for Food Systems of RAS (VNIITeK - Branch of Gorbatov Research Center for Food Systems)

78, Shkolnaya Street, Vidnoe

Moscow region, 142703, Russia

www.vniitek.ru

E-mail: labtech45@yandex.ru

Keywords: review, vegetable fermentation process, lactic acid microorganisms, safety and quality of finished products.

Conflict of interest: The authors declare no conflict of interest.

For citation: Posokina N.E., Zakharova A.I. Lactic acid bacteria, creating the optimal starting conditions for fermentation of cabbage. Vegetable crops of Russia. 2019;(4):80-84 (In Russ.)

https://doi.org/10.18619/2072-9146-2019-4-80-84

Received: 23.04.2019

Accepted: 25.08 .2019
Молочнокислые микроорганизмы, создающие оптимальные стартовые условия для процесса ферментации капусты белокочанной

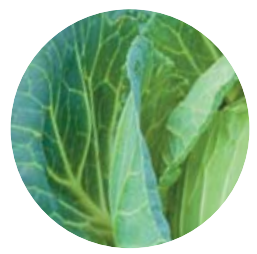

АННОТАЦИЯ

Актуальность

Ферментация овощей обычно осуществляется традиционным способом (спонтанная ферментация с использованием нативной микрофлоры), однако качество готовой продукции при этом достаточно сложно спрогнозировать. Очень часто из-за низкого начального количества молочнокислых бактерий или их низкой активности результат процесса остается непредсказуемым, что может привести к потере значительного количества продукта. В ферментации овощей участвуют несколько видов факультативно анаэробных молочнокислых бактерий. Для того чтобы контролировать процесс ферментации и сделать его направленным, необходимо изучить, какие именно молочнокислые бактерии участвуют в процессе ферментации, период, в который происходит их рост и отмирание, и как это влияет на органолептические свойства готовой продукции, а также исследовать активность молочнокислых микроорганизмов в процессе ферментирования. При ферментации овощей остаются не только первоначальные питательные вещества, такие как витамин С, аминокислоты, пищевые волокна и др., но также развиваются функциональные микроорганизмы, такие как молочнокислые бактерии. Ферментация оказывает важное влияние на качество и вкус, поэтому очень важно изучить процесс ферментации, микробное разнообразие и изменение питательных веществ и химических элементов в процессе ферментации. Снижение темпов или предотвращение микробиологической порчи пищевых продуктов основано на четырех основных принципах: минимизация контаминации продукта микроорганизмами; подавление роста и размножения микроорганизмов-контаминантов; уничтожение микроорганизмов-контаминантов; удаление микроорганизмов-контаминантов. Ферментация основана на сочетании первых трех принципов и достигается созданием условий для роста специфических микроорганизмов, которые могут придавать пищевым продуктам желаемый вкус, аромат, текстуру и внешний вид.

Результаты

Данный обзор посвящен научным аспектам ферментирования овощей, в т.ч. культурам, способствующим созданию оптимальных условий для развития основного пула молочнокислых микроорганизмов, получению готовой продукции высокого качества и предотвращению микробной порчи. Показано, что на первом этапе ферментации определяющую роль играют лактобациллы рода L. mesenteroides. Именно от их "работы" по созданию оптимальных условий для развития целевой молочнокислой микрофлоры зависит качество готовой продукции. Данный факт нужно учитывать при создании промышленных бактериальных заквасок - “стартерных культур" для проведения направленного процесса ферментации овощей.

\section{Lactic acid bacteria, creating the optimal starting conditions for fermentation of cabbage}

ANNOTATION

Relevance

Fermentation of vegetables is usually carried out in the traditional way (spontaneous fermentation using native microflora), but the quality of the finished product is difficult to predict. Very often, due to the low initial amount of lactic acid bacteria or their low activity, the result of the process remains unpredictable, which can lead to the loss of a significant amount of product. In the fermentation of vegetables involved several types of facultatively anaerobic lactic acid bacteria. In order to control the fermentation process and make it directed, it is necessary to study which lactic acid bacteria are involved in the fermentation process, the period in which their growth and death, and how it affects the organoleptic properties of the finished product, as well as to study the activity of lactic acid microorganisms in the fermentation process. When fermentation of vegetables are not only the original nutrients such as vitamin C, amino acids, dietary fibers, etc., but also develop functional microorganisms such as lactic acid bacteria. Fermentation has an important effect on the quality and taste, so it is very important to study the fermentation process, microbial diversity and changes in nutrients and chemical elements in the fermentation process. Reducing the rate or preventing microbial spoilage of food is based on four main principles: minimization of product contamination by microorganisms; suppression of growth and reproduction of microorganisms-contaminants; destruction of microorganisms-contaminants; removal of microorganisms-contaminants. Fermentation is based on a combination of the first three principles and is achieved by creating conditions for the growth of specific microorganisms that can give food the desired taste, aroma, texture and appearance.

Results

This review is devoted to the scientific aspects of vegetable fermentation, including crops that contribute to the creation of optimal conditions for the development of the main pool of lactic acid microorganisms, the production of finished products of high quality and the prevention of microbial spoilage. It is shown that at the first stage of fermentation lactobacilli of the genus $L$. mesenteroides play a determining role. It is their "work" to create optimal conditions for the development of the target lactic microflora depends on the quality of the finished product. This fact should be taken into account when creating industrial bacterial starter cultures - "starter cultures" for the directed process of fermentation of vegetables. 
○ерментация овощей по-прежнему часто осуществляется традиционным способом (спонтанная ферментация), однако качество готовой продукции при этом достаточно сложно спрогнозировать. Очень часто из-за низкого начального количества молочнокислых бактерий или их низкой активности результат процесса остается неопределенным. В ферментации овощей участвуют несколько видов факультативно анаэробных молочнокислых бактерий. Для того чтобы контролировать процесс ферментации и сделать его направленным, необходимо изучить, какие именно молочнокислые бактерии участвуют в процессе ферментации, период, в который происходит их рост и отмирание, и как это влияет на органолептические свойства готовой продукции, а также исследовать активность молочнокислых микроорганизмов в процессе ферментирования.

Капуста является одним из самых популярных продуктов, который в основном ферментируется с добавлением различных овощей. При ферментации остаются не только первоначальные питательные вещества, такие как витамин С, аминокислоты, пищевые волокна и др., но также развиваются функциональные микроорганизмы, такие как молочнокислые бактерии. Ферментация оказывает важное влияние на качество и вкус капусты, поэтому очень важно изучить процесс ферментации, микробное разнообразие и изменение питательных веществ и химических элементов в процессе ферментации [1].

Процессы ферментации пищевых продуктов часто приводят к глубоким изменениям вкуса по сравнению с исходными ингредиентами. Однако ферментированные продукты обычно представляют собой очень сложные экосистемы с активными ферментными системами из ингредиентов, взаимодействующих с метаболической активностью ферментационных организмов. Такие факторы, как добавленная соль, размеры частиц, температура и уровень кислорода также оказывают важное влияние на процесс ферментации. Очень важна роль молочнокислых бактерий в изменении соединений, которые помогают определить характер ферментированных продуктов [2].

Исследования, в которых использовали традиционные биохимические методы изучения ферментации квашеной капусты, показали, что в процессе ферментации задействованы четыре основных вида молочнокислых бактерий: Leuconostoc mesenteroides,
Lactobacillus plantarum, Pediococcus pentosaceus и Lactobacillus brevis.

L. mesenteroides является, пожалуй, наиболее преобладающим видом молочнокислых бактерий, найденных во фруктах и овощах, которые отвечают за инициирование ферментации капусты и других овощей. Осознавая практическое значение $L$. mesenteroides в ферментации была определена целая геномная последовательность L. mesenteroides ATCC 8293. L. mesenteroides представляет собой упрощенную, но уникальную модель с интересными характеристиками. Представленные данные оценивают L. mesenteroides как предмет для изучения гетероферментативного метаболизма молочнокислых бактерий [3]

Также и в других видах капусты, таких как кимчи, L. mesenteroides является одной из наиболее преобладающих молочнокислых бактериальных групп во время ферментации. Кимчи - традиционная корейская ферментированная пища, производится путем ферментации овощей, таких как капуста китайская и редька, с различными приправами. Исследования с использованием традиционных и молекулярных методов показали, что различные виды молочнокислых бактерий, такие как Leuconostoc mesenteroides, Lactobacillus sakei и Weissella koreensis, вероятно, будут ключевыми игроками, ответственными за ферментацию кимчи. Членами рода Leuconostoc являются гетероферментативные молочнокислые бактерии, которые обычно доминируют в ранние и средние фазы ферментации кимчи и, как известно, входят в состав молочнокислых бактерий, которые определяют ароматы кимчи. Штамм $L$. mesenteroides, обозначенный J18, был выделен из baechu (китайская капуста) кимчи, ферментированной при $4^{\circ} \mathrm{C}$ для исследования полной последовательности генома[4].

Вместе с изучением молочнокислых организмов и их влияния на ферментацию, изучали использование минеральных солей, трав и специй в сочетании с изолированными штаммами молочнокислых бактерий ( $L$. mesenteroides и Pediococcus dextrinicus) при ферментации квашеной капусты и сока квашеной капусты. Использовали следующие травы и специи: анис, семена укропа, тмин, укроп, чеснок и мяту. Минеральную соль с низким содержанием натрия использовали, потому что это соответствует общей тенденции в промышленно развитых странах по снижению уровня соли в пищевых продуктах для предотвращения сердечно-сосудистых заболеваний. С помо- щью трав и специй в сочетании с изолированными штаммами молочнокислых бактерий в качестве заквасок и минеральной соли с низким содержанием $\left(\mathrm{Na}^{+}\right)$можно было производить квашеную капусту и сок квашеной капусты с хорошими микробиологическими и органолептическими качествами. Во всех обработках вариантов испытаний $\mathrm{pH}$ был ниже 4 в течение 20-25 часов, что показывает значительно более короткое время ферментации по сравнению с естественной ферментацией квашеной капусты. Количество дрожжей и плесневых грибов быстро снизилось во время ферментации, и ни в одном из соков квашеной капусты не обнаружено ни дрожжей, ни грибов, ни энтеробактерий. В итоге можно отметить, что данные продукты могут стать альтернативой для потребителей, которые предпочитают ферментированные продукты с низким содержанием соли [5].

Влияние L. mesenteroides на ферментацию капусты с пониженной концентрацией соли изучали для того, чтобы определить, будет ли добавление стартерной культуры способствовать получению квашеной капусты с воспроизводимым и приемлемым химическим составом и органолептическими характеристиками. Химический анализ проб рассола квашеной капусты показал, что ферментация с добавлением $1 \%$ поваренной соли и L. mesenteroides проходила быстрее, с более равномерным $\mathrm{pH}$, сокращено количество $\mathrm{NaCl}$ на 50\%, сохранены текстура и вкусовые качества, а также добавление $L$. mesenteroides coхранило твердую хрустящую текстуру квашеной капусты без постороннего привкуса в конечном продукте.

Для определения штаммов $L$. mensenteroides и их фенотипических характеристик, касающихся роли бактерий в ферментировании, из различных видов овощей были выделены штаммы, синтезирующие внеклеточный полисахарид декстран на среде с $10 \%$ сахарозы. Исследования признаков ферментации молочнокислых бактерий являются первым шагом в отборе штаммов, способных производить достаточное количество кислоты. Следующий этап заключается в выборе наиболее подходящих штаммов $L$. mesenteroides в качестве стартовых культур для контролируемой ферментации овощей [6]. Авторами [7] были выделены низинустойчивые штаммы L. mesenteroides для определения потенциального использования в качестве стартовой культуры для ферментации капусты. Обнаружено, что некоторые штаммы 
L. mesenteroides могут быть адаптированы к высоким уровням резистентности низина, в то время как другие нет.

В результате исследований было определено влияние низина и соли на кинетику роста низин-устойчивых штаммов отдельно и в комбинации. Именно пищевая соль оказалась важнейшим фактором, влияющим на удельные скорости роста штаммов, а не синергетический эффект между низином и солью. Низин-устойчивые штаммы были неизменны в их способности быстро производить гетеролактические конечные продукты ферментации. Таким образом, использование штаммов $L$. mesenteroides в качестве заквасок в сочетании с низином может продлить гетеролактическую фазу ферментации капусты.

Другими низин-устойчивыми штаммами, которые применяли в качестве стартовых культур в процессе ферментации в модельной среде квашеной капусты, были $L$. mesenteroides NCK 293 и низин производственный - Lactococcus lactic подвид lactis NCK 401. Их применяли как отдельные стартовые культуры, так и в комбинации. Выбор низин- устойчивых штаммов $L$. mesenteroides оценивали по их чувствительности к низину, чтобы определить стойкую культуру, которая могла бы расти в комбинации со штаммом, продуцирующим низин. L. mesenteroides NCK 293 был выбран для консорциума стартерных культур из-за его способности хорошо расти в данных условиях. Рост L. mesenteroides был похож, как в присутствии, так и в отсутствии Lactococcus lactic подвид lactis. В результате исследований авторами была разработана новая стартерная культура, которая соединяет в себе естественный низинустойчивый L. mesenteroides, изолированный из рассола капусты, и низин-производящий Lactococcus lactis подвид lactis, изолированный из квашеной капусты [8].

L. mesenteroides считается доминирующим видом на ранней гетероферментативной стадии ферментации. Однако имеется мало информации о разнообразии видов и штаммов Leuconostoc, участвующих в ферментации квашеной капусты. Для их определения были выделены молочнокислые бактериальные штаммы из рассолов, отобранных после 7 дней промышленной ферментации квашеной капусты, и шесть штаммов были выбраны на основе восприимчивости к бактериофагам.
Наблюдался бактериальный рост в капустном соке, а конечные продукты ферментации идентифицировались, определялись количественно и сравнивались с L. mesenteroides. Идентификация указала, что шесть выбранных изолятов капусты были штаммами Leuconostoc fallax. Модели роста и ферментации изолятов L. fallax были очень похожи на штаммы L. mesenteroides. Конечный $\mathrm{pH}$ ферментации капустного сока составлял 3,6, а основными конечными продуктами ферментации были молочная кислота, уксусная кислота и маннит. В связи с тем, что малолактическая активность молочнокислых бактерий может оказать существенное влияние на химические свойства ферментированной капусты, то важно определить, какие виды Leuconostoc преобладают в ферментации [9].

Штамм L. mesenteroides LMG 7954 и штамм Lactobacillus plantarum L4 применяли для контролируемой ферментации кочанов капусты. Наблюдали за параметрами контролируемой и спонтанной ферментации, включая антимикробный эффект рассола капусты, полученного в конце обеих ферментаций. Начальные культуры, применяемые для ферментации кочанов капусты, позволили снизить концентрацию $\mathrm{NaCl}$ с 4,0\% до 2,5\%, значительно ускорить процесс ферментации на 14 дней и улучшить качество продукта. Полученные кочаны квашеной капусты считаются пробиотическим продуктом, поскольку количество жизнеспособных пробиотических клеток в конечном продукте было выше, чем $10^{6}$ колониеобразующих единиц (KOE) на грамм продукта. Результаты этого исследования показали, что применение $L$. mesenteroides LMG 7954 вместе с Lb. plantarum L4, положительно повлияли на ферментацию, улучшив качество конечного продукта с добавленными пробиотическими свойствами, значительно сократив время ферментации и предлагая возможность низких солевых ферментаций [10].

Другими стартовыми культурами для изучения их влияния на процесс ферментации и качество квашеной капусты были выбраны $L$. mesenteroides и L. lactis ssp. Процесс ферментации квашеной капусты проводили в 3 цикла и в 4-х повторностях в контролируемых условиях $(2,5 \%$ $\left.\mathrm{NaCl}, 21^{\circ} \mathrm{C}\right)$ с использованием стартовых культур (контроль; Leuconostoc mesenteroides - 700 млн КОЕ/мл; Lactococcus lactis ssp. lactis - 500 млн
КОЕ/мл; сок от предыдущей ферментации). Каждый цикл длился 28 дней. Были изучены микробиологические и химические характеристики квашеной капусты в течение 28-дневного периода ферментации. Содержание молочнокислых бактерий, концентрацию молочной кислоты и рН среды контролировали ежедневно. По завершении каждого цикла ферментации следовало определение органолептических свойств конечного продукта, который наблюдался в течение 6 месяцев с целью определения срока годности. Наилучшие результаты относительно качества квашеной капусты и срока годности были достигнуты при использовании варианта с использованием бактерии L. lactis ssp. в качестве стартовой культуры. Конечный продукт обладал отличными органолептическими свойствами, которые оставались неизменными в течение 6 месяцев наблюдения [11].

Исследования влияния $L$. mesenteroides с малолактической активностью и без нее (MDC+MDC-) на органолептические и химические свойства квашеной капусты показали, что малолактическая активность L. mesenteroides не оказывает важного влияния на ферментацию квашеной капусты, так как органолептических различий между MDC+ и MDCне обнаружено. Кроме того, профили соединения серы получаемой квашеной капусты практически идентичны. А посол капусты 0,5\% $\mathrm{NaCl}$ привел к значительным изменениям микробиологических и химических процессов на ранних стадиях ферментирования квашеной капусты и к нежелательным изменениям во вкусе квашеной капусты. Сульфатно-консервированная капуста отличается от ферментированной капусты, как органолептическими свойствами, так и составом серы, что еще раз доказывает, что ферментация имеет важное значение для создания вкуса квашеной капусты, за счет начальной скорости подкисления, метаболизма серы или сочетания этих факторов [12].

По мере увеличения масштабов промышленной ферментации овощей во всем мире утилизация солевых (хлоридных) отходов, образующихся при переработке этих продуктов, становится серьезной проблемой. Разработка новой технологии снижения количества соли, используемой при ферментации овощей, может потребовать более глубокого понимания экологии этих ферментаций, а также может потребовать использования стартерных культур.

Leuconostoc mesenteroides 
является преобладающим микроорганизмом на ранних стадиях ферментации капусты и оказывает большое влияние на вкус и качество продукта ферментации, поэтому важной задачей являлось изучение характеристик генома L. mesenretoides, a также разнообразие геномов молочнокислых бактерий (Lactobacillus gasseri, L. casei, L. bulgaricus, and L. brevis, L. mesenteroides, Oenococcus oeni, Lactococcus cremoris, $P$. pentosaceus, Streptococcus thermophilus, Brevibacterium linens) и формирование их в 1 геном консорциум. Данные показали, что бактериофаги могут играть важную роль в естественной смене молочнокислых бактерий [13]. Исследование последовательности бактериофага Leuconostoc mesenteroides $\Phi 1-A 4$, выделенного в процессе промышленной ферментации овощей, представляет собой первую полную геномную и молекулярную характеристику фага Leuconostoc и результаты исследования могут положить начало развитию технологии управления фагами. Ферментация овощей зависит от правильной последовательности различных молочнокислых бактерий. Инициирует ферментацию L. mesenteroides. По мере протекания процесса ферментации, L. mesenteroides отмирает, а завершает ферментацию другие молочнокислые бактерии. Фаг Ф1A4, поражающий L. mesenteroides, имеет существенное влияние на развитие вкуса квашенной капусты. В связи с чем нужно отметить, что правильное чередование молочнокислых микроорганизмов непосредственно определяет качество и безопасность готовой ферментированной продукции [14].

\section{Бактериофаги}

Leuconostoc, Oenococcus и Weissella образуют группу родственных молочнокислых бактерий, которые когда-то разделяли имя Leuconostoc. Большинство промышленных штаммов Leuconostoc можно классифицировать как L. mesenteroides или L. pseudomesenteroides. Они являются важными производителями аромата в молочнокислых ферментациях, и они инициируют почти все растительные ферментации. Поэтому бактериофаги, атакующие штаммы Leuconostoc, могут отрицательно влиять на производственный процесс. Бактериофаги, атакующие штаммы Leuconostoc, впервые были зарегистрированы в 1946 году. Фаги Leuconostoc, Oenococcus и Weissella присутствуют во многих типах ферментаций, связанных с продуктами питания, где они несут ответственность за различные дефекты в производстве. Большинство описанных фагов были выделены из образцов молочных продуктов, где они атакуют штаммы стартера Leuconostoc и впоследствии способствуют дефектам образования аромата и $\mathrm{CO}_{2}$. Другое назначение Leuconostoc и фаз Weissella - различные овощные ферментации, наиболее важные из которых кимчи и ферментация капусты. Все фаги Leuconostoc, Oenococcus и Weissella относятся к роду Caudovirales c Siphoviridae, Podoviridae и Myoviridae. Сообщалось о 13 полных геномах фагов, заражающих Leuconostoc и Weissella. Среди них литические фаги Leuconostoc, принадлежащие Siphoviridae, имеют высокое сходство в общем составе, независимо от окружающей среды, из которой они были выделены. До сих пор были установлены тесты на основе ПЦР для обнаружения Iytic Leuconostoc и фагов Oenococcus. Однако развитие дальнейших подробных знаний о генетическом разнообразии фагов Leuconostoc, Oenococcus и Weissella, например, фагов Myoviridae из ферментов квашеной капусты, а также умеренных фагов необходимо для обеспечения лучшей таксономии, контроля и выявления стратегий для этих групп фагов [10].

Для исследования характеристик и идентифицикации бактериофагов из ферментированной капусты в качестве закваски использовали молочнокислые бактерии L. mesenteroides LA10. Было выявлено, что бактериофаги присутствовали в образцах с первого дня процесса ферментации после инокуляции штаммами $L$. mesenteroides. При этом рассмотренные фаги, активные в присутствии Leuconostoc, были охарактеризованы как фаги молочного происхождения, принадлежащие семье Siphoviridae [15].

Исследовали экологию фагов в промышленной ферментации огурцов, с помощью шести представительных фагов: $W$. cibaria, $W$. paramesenteroides, L. plantarum и два L. brevis. Из полученных данных видно, что фаги в изобилии присутствовали в ферментации огурцов, тем самым оказывали влияние на бактериальную экологию и динамику ферментации. Анализ показал, что контроль за управлением фагов необходим для регулирования нормального протекания процесса ферментации в присутствии закваски [16].

Экологию бактериофагов в растительных ферментациях изучали с помощью восьми охарактеризованных фагов следующих представителей: четыре L. mesenteroides, один L. pseudomesenteroides, два L. plantarum и один L. brevis, которые принадлежа- ли к семейству Myoviridae или Siphoviridae. При этом было выявлено, что фаги играют важную роль в микробной экологии и последовательности разновидностей молочнокислых бактерий в растительных ферментациях для достижения высокого качества стабильного продукта с типичным ароматом квашеной капусты [17].

На процесс ферментации квашеной капусты могут влиять технологические, микробиологические и сырьевые факторы: хлорид натрия, углеводы, температура, стартерные культуры. Бактериофаги в ферментации квашеной капусты не вызывают особых проблем, так как их распространение внутри ферментера очень ограничено. Молочная кислота, полученная в процессе ферментации капусты, обычно состоит из двух изомеров L -(+) и D-(-) формах. Большая потребность существует в продуктах, содержащих преимущественно L-(+) - молочной кислоты, а исследование гетероферментативных лактобацилл в ферментации квашеной капусты привело к выделению штаммов, характеризующихся исключительно образованием именно этой кислоты. Такая квашеная капуста производится с помощью применения стартерной культуры Lb. Sakei, которая способна даже подавлять штаммы, инициирующие брожение L. mesenteroides. В связи с чем можно сделать вывод, что молочнокислые бактерии, участвующие в ферментации квашеной капусты, улучшают свойства квашеной капусты и помогают укреплению здоровья человека [18].

Для оптимизации процесса ферментации белокочанной капусты авторами был проработан хемометрический подход. Целью данного подхода являлась оптимизация процесса ферментации целых кочанов белокочанной капусты сорта Futoški и гибрида Bravo. Оба сорта капусты подвергали процессу ферментации с добавлением 1-2\% $\mathrm{NaCl}$ при температуре $18 \ldots 22^{\circ} \mathrm{C}$. В течение 80 дней проводили мониторинг содержания различных органических кислот в листьях капусты и рассоле (щавелевая, молочная, уксусная, яблочная, лимонная, янтарная, муравьиная). Анализ органических кислот при ферментации сорта Futoški и гибрида Браво показал, что ферментация происходит медленнее в гибридах, и соль гораздо медленнее диффундирует в ткань капусты, что приводит к медленному росту содержания кислот. Кочаны капусты сорта Futoški достигли конца ферментации через 20 дней, а гибрид Bravo достиг конца 
ферментации через 50 дней. Анализ и сравнение двух сортов капусты, показали, что сербский сорт Futoški является более подходящим материалом для ферментации капустных кочанов, чем гибрид Bravo. Уплотненные гибридные кочаны капусты, возможно, требуют более высокой концентрации соли для процесса ферментации [19].

Анализ литературы показал важность первого этапа ферментации для конечного качества овощей, в котором определяющую роль играют лактобациллы рода L. mesenteroides. Именно от их «работы» по созданию оптималь- ных условий для развития целевой молочнокислой микрофлоры, в конечном итоге, и зависит качество готовой продукции. Данный факт нужно учитывать при создании промышленных бактериальных заквасок - «стартерных культур" для проведения направленного процесса ферментации овощей.

\section{Об авторах:}

Посокина Наталья Евгеньевна - зав. лабораторией технологии консервирования, кандидат техн. наук

SPIN 3326-0083

Захарова Анна Ивановна - старший научный сотрудник, аспирант

\section{About the authors:}

Nataliya E. Posokina - Head of the laboratory,

Candidate of Technical Sciences (Ph.D.)

Anna I. Zakharova - Senior Researcher

\section{- Литература}

1. Zhang Yu-Long, Hu Ping, Zhan Jian-Long. Research of fermented sauerkraut and its advancement // Journal of Food Safety and Quality. - 2014. Vol.5. - №12. - P.3998-4003.

2. McFeeters R.F. Fermentation Microorganisms and Flavor Changes in Fermented Foods // Journal of food science. - 2004. - Vol. 69. - №1. P.35-37.

3. Plengvidhya Vethachai. Microbial ecology of sauerkraut fermentation and genome analysis of lactic acid bacterium Leuconostoc mesenteroides ATCC 8293 // DPhil Thesis. Raleigh, N.C.: North Carolina State Univ. - 2003. 4. Ji Young Jung, Seung Hyeon Lee, Se Hee Lee and Che Ok Jeon. Complete Genome Sequence of Leuconostoc mesenteroides subsp. mesenteroide Strain J18, isolated from kimchi // Journal of Bacteriology. - 2012. №194(3). - P.730 -731.

5. Wiander Hannu B., Korhonen J.T. Preliminary studies on using LAB strains isolated from spontaneous sauerkraut fermentation in combination with mineral salt, herbs and spices in sauerkraut and sauerkraut juice fermentations // Agricultural and Food Science. - 2011. - Vol. 20. - P.176-182.

6. Dimic G.R. Characteristics of the Leuconostoc mesenteroides strains from fresh vegetables // APTEFF. - 2006. - Vol. 37. - P.3-10

7. Breidt F., Crowley K.A., Fleming H.P. Isolation and characterization of nisin-resistant Leuconostoc mesenteroides for use in cabbage fermentations // Applied and Environmental Microbiology. - 1993. - Vol. 59. - №11. - P.3778-3783

8. Harris L.J., Fleming H.P., Klaenhammer T.R. Novel paired starter culture system for sauerkraut, consisting of a nisin-resistant Leuconostoc mesenteroides strain and a nisin-producing Lactococcus lactis strain // Applied and Environmental Microbiology. - 1992. - Vol.58. - №5. - P.1484-1489.

9. Barrangou R., Yoon Sung-Sik, Jr F.B. Fleming H.P., Klaenhammer T.R Identification and characterization of Leuconostoc fallax strains isolated from an industrial sauerkraut fermentation // Applied and Environmenta Microbiology - 2002 - Vol. 68 - №6 - P.2877-2884

10. Beganovic J., Pavunc A. L., Gjuracic K., Spoljarec M., Suskovic J., Kos B. Improved Sauerkraut Production with Probiotic Strain Lactobacillus plan tarum L4 and Leuconostoc mesenteroides LMG 7954 // Journal of Food Science - 2011 - Vol. 76 - №2 - M124-M129

11. Kristek S., Beslo D., Pavlovic H., Kristek A. Effect of Starter Cultures L mesenteroides and L. lactis ssp. lactis on Sauerkraut Fermentation and Quality // Czech Journal of Food Sciences. - 2004. - Vol. 22. - №4. P.125-132.

12. Johanningsmeier S.D., Fleming H.P., Thompson R.L, McFeeters R.F. Chemical and sensory properties of sauerkraut produced with Leuconostoc mesenteroides starter cultures of differing malolactic phenotypes // Journal of Food Science. - 2005. - Vol. 70. - №5. - P.343-349.

13. Breidt F Jr. A genomic study of Leuconostoc mesenteroides and the molecular ecology of sauerkraut fermentations // Journal of food science. 2004. - Vol. 69. - №1. - P.30-32.

14. Lu Z., Altermann E., Breidt F., Kozyavkin S. Sequence analysis of Leuconostoc mesenteroides bacteriophage $\Phi 1-\mathrm{A} 4$ isolated from industrial vegetable fermentation // Applied and Environmental Microbiology. - 2010 - Vol. 76 - №6. - P.1955-1966.

15. Yoon S.S., Barrangou-Poueys R., Breidt F.Jr., Klaenhammer T.R., Fleming H.P. Isolation and Characterization of Bacteriophages from Fermenting Sauerkraut // Applied and Environmental Microbiology. - 2002. - Vol. 68. - №2. - P.973-976

16. Lu Z., Perez-Diaz I. M., Hayes J. S., Breidt F. Bacteriophage Ecology in a Commercial Cucumber Fermentation // Applied and Environmental Microbiology. - 2012. - Vol. 78. - №24. - P.8571-8578

17. Lu Z., Breidt F., Plengvidhya V., Fleming H. P. Bacteriophage Ecology in Commercial Sauerkraut Fermentations // Applied and Environmental Microbiology - 2003. - Vol. 69. - №6. - P.3192-3202

18. Holzapfel W., Schillinger U., Buckenhbskes H. Sauerkraut // Handbook of fermented functional foods, 2nd ed. - 2008. - Chapter 14 - P.343-361

19. Cvetcovic B., Pezo L., Mandic A., Novakovic A., Pestoric M., Kevresan Z., Mastilovic J. Chemometric approach to optimization of white cabbage fermentation hemometrijski pristup optimizacije procesa fermantacije belog kupusa // Journal on processing and energy in agriculture. - 2014. - Vol. 18 - №2. - P.88-90.

20. Einson J.E., Rani A., You X., Rodriguez A.A., Randell C.L., Barnaba T. Mammel M.K., Kotewicz M.L., Elkins C.A., Sela D.A. Vegetable Fermentation Facility Hosts Distinct Microbiomes Reflecting the Production Environment / Applied and Environmental Microbiology. - 2018. - Vol. 84. - №22. - P.1-55

\section{- References}

1. Zhang Yu-Long, Hu Ping, Zhan Jian-Long. Research of fermented sauerkraut and its advancement // Journal of Food Safety and Quality. - 2014. Vol.5. - №12. - P.3998-4003.

2. McFeeters R.F. Fermentation Microorganisms and Flavor Changes in Fermented Foods // Journal of food science. - 2004. - Vol. 69. - №1. P.35-37.

3. Plengvidhya Vethachai. Microbial ecology of sauerkraut fermentation and genome analysis of lactic acid bacterium Leuconostoc mesenteroides ATCC 8293 // DPhil Thesis. Raleigh, N.C.: North Carolina State Univ. - 2003.

4. Ji Young Jung, Seung Hyeon Lee, Se Hee Lee and Che Ok Jeon. Complete Genome Sequence of Leuconostoc mesenteroides subsp. mesenteroides Strain J18, isolated from kimchi // Journal of Bacteriology. - 2012. №194(3). - P.730 -731.

5. Wiander Hannu B., Korhonen J.T. Preliminary studies on using LAB strains isolated from spontaneous sauerkraut fermentation in combination with mineral salt, herbs and spices in sauerkraut and sauerkraut juice fermentations // Agricultural and Food Science. - 2011. - Vol. 20. - P.176-182.

6. Dimic G.R. Characteristics of the Leuconostoc mesenteroides strains from fresh vegetables // APTEFF. - 2006. - Vol. 37. - P.3-10.

7. Breidt F., Crowley K.A., Fleming H.P. Isolation and characterization of nisin-resistant Leuconostoc mesenteroides for use in cabbage fermentations // Applied and Environmental Microbiology. - 1993. - Vol. 59. - №11. - P.3778-3783

8. Harris L.J., Fleming H.P., Klaenhammer T.R. Novel paired starter culture system for sauerkraut, consisting of a nisin-resistant Leuconostoc mesenteroides strain and a nisin-producing Lactococcus lactis strain // Applied and Environmental Microbiology. - 1992. - Vol.58. - №5. - P.1484-1489.

9. Barrangou R., Yoon Sung-Sik, Jr F.B. Fleming H.P., Klaenhammer T.R Identification and characterization of Leuconostoc fallax strains isolated from an industrial sauerkraut fermentation // Applied and Environmental Microbiology. - 2002. - Vol. 68. - №6 - P.2877-2884.

10. Beganovic J., Pavunc A. L., Gjuracic K., Spoljarec M., Suskovic J., Kos B. Improved Sauerkraut Production with Probiotic Strain Lactobacillus plantarum L4 and Leuconostoc mesenteroides LMG 7954 // Journal of Food Science. - 2011. - Vol. 76. - №2. - M124-M129.

11. Kristek S., Beslo D., Pavlovic H., Kristek A. Effect of Starter Cultures L. mesenteroides and L. lactis ssp. lactis on Sauerkraut Fermentation and Quality // Czech Journal of Food Sciences. - 2004. - Vol. 22. - №4. P.125-132.

12. Johanningsmeier S.D., Fleming H.P. Thompson R.L., McFeeters R.F. Chemical and sensory properties of sauerkraut produced with Leuconostoc mesenteroides starter cultures of differing malolactic phenotypes // Journal of Food Science. - 2005. - Vol. 70. - №5. - P.343-349.

13. Breidt F Jr. A genomic study of Leuconostoc mesenteroides and the molecular ecology of sauerkraut fermentations // Journal of food science. 2004. - Vol. 69. - №1. - P.30-32.

14. Lu Z., Altermann E., Breidt F., Kozyavkin S. Sequence analysis of Leuconostoc mesenteroides bacteriophage $\Phi 1-A 4$ isolated from industria vegetable fermentation // Applied and Environmental Microbiology. - 2010. - Vol. 76 - №6 - P 1955-1966.

15. Yoon S.S., Barrangou-Poueys R., Breidt F.Jr., Klaenhammer T.R., Fleming H.P. Isolation and Characterization of Bacteriophages from Fermenting Sauerkraut // Applied and Environmental Microbiology. - 2002. - Vol. 68. - №2. - P.973-976

16. Lu Z., Perez-Diaz I. M., Hayes J. S., Breidt F. Bacteriophage Ecology in a Commercial Cucumber Fermentation // Applied and Environmenta Microbiology. - 2012. - Vol. 78. - №24. - P.8571-8578

17. Lu Z., Breidt F., Plengvidhya V., Fleming H. P. Bacteriophage Ecology in Commercial Sauerkraut Fermentations // Applied and Environmenta Microbiology - 2003. - Vol. 69. - №6. - P.3192-3202

18. Holzapfel W., Schillinger U., Buckenhsskes H. Sauerkraut // Handbook of fermented functional foods, 2nd ed. - 2008. - Chapter 14 - P.343-361

19. Cvetcovic B., Pezo L., Mandic A., Novakovic A., Pestoric M., Kevresan Z. Mastilovic J. Chemometric approach to optimization of white cabbage fermentation hemometrijski pristup optimizacije procesa fermantacije belog kupusa // Journal on processing and energy in agriculture. - 2014. - Vol. 18 - №2. - P.88-90.

20. Einson J.E., Rani A., You X., Rodriguez A.A., Randell C.L., Barnaba T., Mammel M.K., Kotewicz M.L., Elkins C.A., Sela D.A. Vegetable Fermentation Facility Hosts Distinct Microbiomes Reflecting the Production Environment // Applied and Environmental Microbiology. - 2018. - Vol. 84 - №22. - P.1-55 